\title{
La economía feminista frente a la racionalidad económica autointeresada
}

\author{
MARIA MEDINA-VICENT* \\ Universitat Jaume I (España) \\ medinam@uji.es
}

\begin{abstract}
Resumen
El modelo de ciudadanía pretendidamente universal inaugurado con la filosofía moderna junto al predominio de la razón instrumental derivada de la economía neoclásica, confluyen para definir una posición social inferior para las mujeres. La confluencia de ambas construcciones filosóficas, políticas y económicas configura un espacio económico de desigualdad de género que debe ser repensado críticamente. Frente a esta situación, nos proponemos abordar el potencial crítico de la economía feminista a la hora de subvertir la desigualdad generada por la preeminencia del modelo del bomo oeconomicus en el mundo actual y la falta de un sujeto político que atienda a las particularidades de otros grupos.
\end{abstract}

Palabras clave: racionalidad económica, ciudadanía, ética económica, economía feminista.

\section{Feminist economics versus self-interested economic rationality}

\begin{abstract}
The model of universal citizenship inaugurated with modern philosophy link to the predominance of instrumental rationality derived from neoclassical economics come together to define a disadvantaged social position of women. The confluence of these philosophical, political and economic constructions builds an economic space of gender inequality that must be approached critically. Faced with this situation, we intend to address the critical potential of feminist economics to subverting the inequality generated by the preeminence of the homo oeconomicus model in economic space, and the lack of a political subject that addresses the particularities of other groups.
\end{abstract}

Key words: economic rationality, citizenship, economic ethics, feminist economics.

\footnotetext{
Profesora Ayudante Doctora en el Dep. de Filosofía y Sociología de la Universitat Jaume I (Castelló de la Plana, España). Doctorado Internacional en el Programa de Ética y Democracia de la UJI con la tesis Género y management en el marco neoliberal. Un análisis crítico para la emergencia de liderazgos feministas (Premio de la Real Academia de Doctores de España 2018 en la categoría de Humanidades). Sus principales líneas de investigación son la filosofía feminista, el liderazgo y los Critical Management Studies.

Este trabajo se enmarca dentro del Proyecto de Investigación Científica y Desarrollo Tecnológico FFI2016-76753-C2-2-P, financiado por el Ministerio Español de Economía y Competitividad.
} 
$\mathrm{El}$ androcentrismo forma parte de los procesos culturales, económicos y políticos sobre los que se construyó la modernidad, y de los cuales somos herederos/as en la actualidad. En las dinámicas androcéntricas todo lo considerado masculino se sitúa en valor por encima de lo considerado femenino, que es menospreciado. Dicho androcentrismo cultural en el cual se inscribe el modelo de ciudadanía universal moderno, unido al predominio de la razón instrumental en el ámbito económico, han definido dicho espacio como un ámbito sin valores morales donde las desigualdades e injusticias se reproducen reiteradamente.

Frente a esta realidad social caracterizada por las estructuras de desigualdad de género, nace el feminismo como hermenéutica de la sospecha (Reverter-Bañón, 2008), ya que tiene por objeto desvelar la artificiosidad y falsedad de la igualdad universal que se predica en el discurso ilustrado. Partiendo de esta idea central, consideramos que trabajando desde la perspectiva crítica de la que se nutre la corriente feminista, podremos desvelar tanto la falsedad de la pretendida universalidad del modelo de ciudadano del proyecto ilustrado, como la falsedad de la racionalidad autointeresada en la que se centra la teoría económica neoclásica. De este modo, partiendo de estas dos intenciones principales, nos hemos propuesto reivindicar que en los puntos en que confluye la racionalidad económica correspondiente al modelo de homo oeconomicus, con la noción de feminidad como naturaleza minusvalorada en el modelo de ciudadanía universal, se generan espacios de exclusión social para las mujeres que hoy en día perviven e impiden la consecución de una verdadera igualdad.

Además, en este artículo nos proponemos sostener que la confluencia de los procesos expuestos en el párrafo anterior ha derivado en una crisis de cuidados a nivel global, que supone grandes retos para las sociedades democráticas. Una crisis, que tal y como veremos más adelante, revela la ineficacia de una economía desprovista de valores que silencia el papel de las mujeres en el desarrollo de las sociedades. Desde nuestro punto de vista, el rol del feminismo en este contexto es vital, no solamente para poner en evidencia la posibilidad de reconstruir una teoría económica que atienda a las disyuntivas humanas que se producen hoy alrededor del mundo, sino también para rearticular una lucha feminista de corte político (Medina-Vicent, 2018b) que acabe con las evasivas de los Estados a hacer frente a las necesidades de cuidados y bienestar social de la ciudadanía (Castro, 2016). 
1. EL NACIMIENTO DE UNA RACIONALIDAD ECONÓMICA AUTOINTERESADA

A partir del surgimiento del concepto de agencia humana conocido como homo oeconomicus, fundamental en la teoría económica moderna, los comportamientos humanos y organizacionales se han inspirado en principios utilitaristas e individualistas. Sin embargo, cabe señalar que la preeminencia de una economía desprovista de valores es fruto de un tiempo histórico y de unos ideales concretos, no de un estado natural de las cosas. En contraposición a la visión predominante de la agencia económica actual, Aristóteles expuso en su Ética a Nicómaco, la inextricable relación que une al campo económico con la ética y la política. En este contexto antiguo, tal y como señala el filósofo Jesús Conill (2004: 81), "los valores éticos son constitutivos de la actividad económica, ya que son una manera de poner en práctica la «recta razón» en dirección al bien del individuo y de la ciudad, conforme a un orden natural y comunitario". Por tanto, la economía se concebía en unión con la ética y la política, ya que a través de las actividades económicas se perseguía el bien de la comunidad, que Aristóteles entendió como la economía doméstica u oikonomía.

Así pues, aunque desde Aristóteles a Adam Smith, la economía ha estado vinculada a la ética, a finales del siglo XVIII e inicios del XIX, la anterior concepción de la economía como un proceso holístico abrió paso a la individualización y a la constitución de la economía como una ciencia autónoma y objetiva (Miedes \& Flores, 2013: 234). Mediante la secularización y autonomía de la economía respecto a la cultura religiosa medieval, asistimos al surgimiento de un individualismo que va a imperar no solamente en el ámbito económico, sino que se va a convertir en eje fundamental de la identidad humana moderna. De esta manera, el individuo moderno será construido como un agente racionalizador y maximizador de beneficios, que regirá sus decisiones por el autointerés, ya que la economía, la política, la religión y la ética, serán percibidas como ámbitos no vinculados. Esta desvinculación ficticia, implica que los agentes económicos rehúsen la responsabilidad moral subyacente a sus actos y decisiones, ya que no conciben el ámbito económico como moral, ni reconocen que las decisiones tomadas en su seno podrán ser morales o inmorales.

En esta línea, la tesis central defendida por la teoría económica neoclásica es que la mayor parte de las decisiones económicas se toman en vistas a conseguir un beneficio personal, es decir, los agentes económicos actúan en base a un comportamiento maximizador de las ganancias personales. Sin embargo, Johansen (1977) cuestiona esta premisa que define el comportamiento en base a un modelo de homo oeconomicus, y expone que 
existen muchas más realidades que no aceptan las premisas de comportamiento egoísta de este modelo de agente económico, realidades que no pueden ser obviadas desde un punto de vista ético.

En este sentido, Johansen expone la necesidad de que la teoría económica moderna considere también aquellas realidades en que los beneficios económicos no son una posibilidad, como por ejemplo, cuando estamos hablando de generar bienes sociales y no privados, bienes que reporten beneficios no solamente al individuo sino al grueso de la sociedad. Por tanto, aunque en la mayor parte de los casos la cuestión central en la economía moderna ha sido confirmar si los individuos "ofrecen siempre una respuesta maximizadora de la ganancia, o por lo menos lo hacen con tanta frecuencia que este supuesto general resulte apropiado para la teoría económica" (Sen, 1986: 197), no existen evidencias suficientes para confirmar dicho presupuesto y cae por su propio peso la idea del autointerés y el egoísmo como base principal del comportamiento económico. A pesar de esta realidad, en el proceso extensivo de este modelo de economía, ha sido clave la creencia generalizada de que en la interacción humana en contextos económicos solamente entran en juego actitudes guiadas por el propio interés (Calvo, 2010: 102).

Sin embargo, resulta importante reivindicar que en la esfera económica no solamente existe un tipo de agente racional neoclásico, encarnado en la figura del homo oeconomicus, sino que pueden, y de hecho coexisten, diferentes tipos de agentes que ponen en juego valores como la equidad (Calvo, 2012; Gintis, 2000) y la reciprocidad (Calvo, 2018). Del mismo modo, nos permite ser conscientes de que "la complejidad de las conductas humanas dentro de la economía no puede reducirse a una racionalidad determinada, a un ser solipsista, amoral y asocial incapaz de ver más allá de su propio interés" (Calvo, 2010: 106), sino que debe ampliarse a la vez que se amplía, o mejor dicho se renuncia, a la visión de la empresa como un ser aislado de lo social, y se reivindica una concepción holística y plural de la misma.

Por otro lado, cabe tener en cuenta que la globalización ha posibilitado una extensión mundial de estas bases de funcionamiento económico centradas en la maximización del beneficio y la lógica del autointerés, agravando las desigualdades entre países y convirtiendo a las empresas en agentes cuya supuesta neutralidad amenaza con acabar con el desarrollo y el bienestar social de diferentes grupos humanos. En esta línea, además de reivindicar el esencial carácter moral de la economía y las organizaciones empresariales (Cortina, 1994; Conill, 2003; García-Marzá, 2004), es preciso realizar una reflexión ética de la esfera económica, porque, siendo un espacio de interacciones humanas, ámbito de interacción de valores morales y razones éticas, no puede escapar de la reflexión moral. Y ésta es una de 
las tareas que emprenderemos en el presente artículo de investigación a través de la propuesta de la economía feminista.

En definitiva, a lo largo de este apartado hemos reflexionado en torno a la operación cultural y simbólica que se refiere a la separación entre economía, política y moral, hecho histórico que desliga al ámbito económico y empresarial de la responsabilidad moral de los actos que se desarrollan en su seno. Reflexionar sobre dicho proceso es necesario si pretendemos identificar los procesos culturales que confluyen para generar un sistema económico desprovisto de valores, que es ajeno a las necesidades de la población y que reproduce y agrava las desigualdades de género. Por esta razón, partiendo de las cuestiones tratadas en este primer apartado, pasaremos a continuación a reflexionar sobre el pretendido carácter universal del concepto de ciudadanía derivado de la Modernidad.

\section{LAS BASES UNIVERSALES DE LA CIUDADANÍA MODERNA}

Anteriormente se ha tratado el proceso de separación entre economía y ética que se produce a lo largo del siglo XVIII, y que supone la preeminencia en época moderna de una concepción de la economía desprovista de valores morales que, a nuestro parecer, legitima la pervivencia de desigualdades de género en el ámbito económico y social. Sin embargo, si deseamos comprender la realidad de la desigualdad de género en el ámbito económico en toda su complejidad, debemos adentrarnos en otros procesos que tienen gran incidencia en dicho fenómeno, esto es, la separación dicotómica entre esfera pública y privada, y la conformación de un concepto de ciudadanía con pretensiones universales, acontecidos con el surgimiento del Estado burgués moderno en el siglo XVII.

El sentido de abordar ambas cuestiones reside en que este conjunto de procesos, en su confluencia, transforman la "diferencia sexual" en "diferencia política" (Mateos Sillero, 2013: 301), rasgo que dificulta la consecución de un estatuto de igualdad jurídica y política de las mujeres en la vida social y la económica. Nuestro objetivo en este apartado es identificar la configuración de un sujeto universal moderno como portador de sentido en la filosofía moderna, un sujeto aparentemente neutral, pero con significados y prejuicios de género asociados (Medina-Vicent, 2013). Todos estos componentes configuran un escenario social de relaciones de poder basadas en el sexo, en que el grupo de hombres tiene poder sobre las mujeres, cuya corporeidad es excluida del sujeto universal racional (Amorós, 2000: 383).

Kate Millett (1995) en su obra Sexual Politics (de 1970) puso de relieve cómo el sexo, una cuestión antes relegada al ámbito privado, era vitalmente una cuestión política, ya que se trataba y se trata de una cuestión de 
poder que debía ser concebida como tal e iluminada por la luz de lo público. La política sexual supone la dominación del sexo masculino sobre el femenino, lo que se configura como la clave para comprender que el papel de las mujeres en la sociedad moderna está condenado a la invisibilidad (Millett, 1995: 72). Esta idea se configuró como un paso fundamental en el desarrollo del feminismo radical de los años setenta del siglo XX, ya que mostró cómo la política hace uso de estrategias de represión del sexo para definir las esferas sociales, y asignar roles sociales, laborales, económicos, etc. a los diferentes grupos en función de su sexo y su cuerpo (ReverterBañón, 2009).

Dichas relaciones de poder de un grupo sobre otro inciden en la formación dicotómica de los espacios sociales modernos: público y privado. Esto nos remite directamente al proceso de constitución política de una nueva sociedad civil y una nueva forma de derecho político que se produce con el surgimiento del Estado Moderno, a lo largo del siglo XVII, y el paso al Estado burgués. A partir de la teoría del contrato social, este nuevo Estado estará formado por un contrato aceptado por aquellos que deseen formar parte de la sociedad, aceptando sus obligaciones como miembros de una comunidad política (Rawls, 2009). Sin embargo, la separación dicotómica entre ambos espacios impide esa pretendida igualdad.

En su obra Segundo Tratado (1689), Locke (2014) fundamentó de forma teórica la separación entre lo público y lo privado, sentando las premisas para la división dicotómica que venimos tratando. Según su definición, en el espacio privado se sitúa la familia nuclear moderna, y debido a que las mujeres no son en este momento propietarias de su cuerpo y destino, quedarán relegadas a este ámbito bajo la tutela del marido, padre o hermano. Refiriéndose al contractualismo de Locke, Pateman (1995) resalta que en el contrato social se construye una "ausencia de libertad natural para las mujeres, ya que existe un derecho natural de los hombres sobre las mujeres" (Beltrán, 1994: 395). Las mujeres aún no han sido consideradas como seres racionales completos y esto les impide participar del contrato social y político teniendo como base la igualdad con respecto a sus conciudadanos varones.

Del hecho de que en ese momento las mujeres aún no han recibido el estatus de "individuo", se desliga la realidad de que no disponen de la libertad necesaria para definir un contrato cualquiera, y esto, en una sociedad contractualista, les otorga una posición de total desventaja. El contrato social será el garante de la libertad de los individuos que establecen una relación mutua para preservar sus intereses, propiedades y libertades dentro del marco social. Sin embargo, dicho contrato entre iguales, solamente entiende por iguales a aquellos con género masculino, las mujeres son ese "otro" que no goza de las mismas condiciones de igualdad para la firma 
contractual. Por esta razón, Pateman (1995: 10) habla de la historia del contrato social como de una historia del contrato sexual, referido al derecho político como derecho patriarcal o derecho sexual, el poder que los varones ejercen sobre las mujeres. Se parte pues de una base contractual desigual, una desigualdad que no es tenida en cuenta por los autores modernos, que dejan de lado, siguiendo la propia terminología de Millett, el sexo entendido como una cuestión política, sin atender las relaciones de poder que subyacen a la cuestión sexual y que condicionan la dinámica social.

Así pues, aunque las bases ideales del liberalismo y las teorías del contrato social son igualitarias, su implantación supondrá que solamente unos pocos sean considerados aptos para desenvolverse en el espacio público. Esto se debe en gran medida a aquellos significados sobre los cuales se construye el sujeto moderno universal, entendido como el modelo a partir del cual va a mirarse el total de la ciudadanía, que se basa en una "igualdad formal y una racionalidad universal profundamente marcados por el sesgo masculino acerca de qué significa ser humano y la naturaleza de la sociedad" (Young, 1990: 91). El sujeto moderno universal de derechos será delimitado por un molde masculino y occidental, en el que no encajarán el resto de seres humanos, incluidas las mujeres. Esta base cultural de nuestras sociedades en su confluencia con la racionalidad económica autointeresada va a resultar central a la hora de comprender la pervivencia de desigualdades de género en dicho ámbito, algo con lo que intenta acabar la economía feminista, que se sitúa en contra del androcentrismo de la racionalidad económica predominante (Carrasco \& Díaz, 2017).

Partiendo de las cuestiones tratadas hasta el momento, nuestra principal tarea en el siguiente apartado será mostrar cómo los pilares sobre los que se construyen las sociedades occidentales actuales, referidos a una economía tradicional centrada en la lógica del homo oeconomicus y un concepto de ciudadanía universal androcéntrico, pueden y deben ser repensados desde las bases del feminismo. A partir de esta reflexión se mostrará que la economía no es un espacio neutral en cuanto a valores morales, sino que las decisiones que se toman en su seno pueden ser inmorales y por tanto susceptibles de denuncia.

\section{LA PROPUESTA CRÍTICA DE LA ECONOMÍA FEMINISTA}

En el presente apartado, nos adentraremos en la propuesta de la economía feminista, ya que dicha corriente nos otorga las herramientas conceptuales para desvelar el carácter androcéntrico del mundo económico. A partir de los años setenta del siglo XX se inicia un análisis crítico de las tradiciones económicas existentes hasta el momento: economía política 
clásica, marxismo, escuela marginalista..., que agruparemos bajo el término de "teorías económicas convencionales", siguiendo la aportación terminológica de la economista Pérez Orozco (2004: 90-92). La economía feminista se nutre de la sospecha crítica que efectúa el feminismo hacia el sistema de patriarcado (Amorós, 2000: 77), en este caso, centrándose en el aspecto económico pero sin dejar de lado una visión holística del mismo. Por esta razón, se caracteriza por una gran heterogeneidad de enfoques, ya que "los intentos de la economía feminista de expandir el contenido de la economía suponen procesos de deconstrucción que cuestionan la centralidad de los mercados (masculinos) y pretenden recuperar los otros femeninos invisibilizados" (Pérez Orozco, 2004: 93).

$\mathrm{Y}$ es que los paradigmas económicos se han centrado históricamente en el análisis de la actividad mercantil, aunque algunas de estas escuelas hayan podido tener una perspectiva más amplia del fenómeno que incluyese el análisis de las relaciones sociales u de otra índole. Por tanto, los mercados se han dibujado como eje central del discurso económico, ejerciendo una identificación de la economía con las esferas de producción, distribución y consumo (Pérez Orozco, 2014b: 60). Dicha operación lleva aparejada la construcción del trabajo como empleo, es decir, supone excluir del análisis los trabajos que son desarrollados más allá de las fronteras delimitadas por la actividad mercantil, trabajos que resultan centrales tanto para el mantenimiento de la vida, como del propio sistema.

Esto supone la construcción de la teoría económica en base a principios dicotómicos como mercado/vida, empleo/no-trabajo, producción/reproducción, etc., conceptos dicotómicos que encuentran su sentido en la epistemología androcéntrica de la Ilustración (Amorós, 1982) en que se basa la teoría económica neoclásica. Se trata de un saber que se presenta completo y objetivo, pero que realmente se encuentra "bajo el control hegemónico de un paradigma - el neoclásico- que se nos presenta sin fisuras" (Carrasco, 2006: 30), un paradigma que promueve la separación entre economía y ética. La economía feminista se encargará de reclamar la constante interconexión entre dichas dicotomías, así como de revelar que la teoría económica neoclásica ha sido la encargada de "racionalizar los roles tradicionales de los sexos - tanto en la familia como en el mercado laboral- y justificar y reforzar de esta manera la situación existente" (Carrasco, 2006: 45). Reclamar dicha interconexión supone denunciar la lógica de una economía sin valores, así como su perpetuación de un sistema dual, que otorga a las mujeres una posición social inferior.

Uno de los componentes que se sustrae de la cuestión vista previamente es que se sitúa todo el interés en el mercado y el trabajo asalariado entendido como empleo. Consecuentemente, se excluyen del análisis un 
gran abanico de trabajos y ámbitos que forman parte de la economía. Hewitson (1999) señala en este sentido que la economía neoclásica produce la pareja perfecta entre presencia masculina y ausencia femenina, es decir, la presencia de los hombres en lo público/productivo y la ausencia de las mujeres en este mismo espacio. Por esta razón, la economía feminista pretende ir más allá de la centralidad de la producción mercantil como objetivo económico básico, porque centrarse en la producción mercantil supone excluir del análisis económico a las mujeres y el rol vital que desempeñan en el desarrollo de la sociedad. Esto nos muestra una vez más la importancia de la escisión público - privado, ya que se ha traducido en una jerarquización de los espacios y de los roles de género, en la que el espacio público productivo, así como las actividades que los hombres realizan en éste, se perciben como relevantes, mientras que el espacio doméstico reproductivo, así como las tareas que en él llevan a cabo de forma mayoritaria las mujeres, son percibidas como secundarias y meros apéndices de los primeros.

Resulta lógico que como resultado de dicha confluencia entre economía instrumental y escisión público-privado encontremos un mundo económico que además de relegar a la mujer a lo privado, promueve la división sexual del trabajo, menospreciando e invisibilizando el trabajo que las mujeres han llevado a cabo tradicionalmente en el ámbito privado, referente a los cuidados y el bienestar de la familia. Con la modernización y el proceso de industrialización, la producción mercantil se separa de la producción doméstica, dando lugar a la familia como centro del autoconsumo familiar, que juega un papel central en la reproducción del sistema capitalista y del mantenimiento de la vida de los/as trabajadores/as (Hartmann, 1981: 393). Esto supone colocar en el centro al mercado, y dejar de lado la radical importancia de las tareas reproductivas realizadas mayoritariamente por mujeres. Es decir, el sistema económico capitalista se construye como una "oposición entre el hogar y el trabajo, entre la maternidad y el trabajo asalariado, entre feminidad y productividad" (Scott, 1993: 406), y esto repercute socialmente en el papel de las mujeres tanto en el ámbito económico como en el laboral, y en la explosión de una crisis de cuidados a nivel global que abordaremos al final de este artículo.

De esta manera, el trabajo reproductivo se encuentra fuera de los flujos del trabajo mercantil o empleo, y es una consecuencia directa de la separación entre esferas pública y privada, y la jerarquización de los espacios sociales en función del sexo (Zein-Elabdin, 2003: 327). Se le denomina trabajo de la reproducción "para diferenciarlo del trabajo de la producción (de bienes y servicios), puesto que éste es el único reconocido, económica y socialmente como trabajo, en las sociedades industrializadas" (Carrasquer et al., 1998: 96). El trabajo de reproducción se identifica con 
las emociones, el amor, y la familia, algo que sirve para excluirlo de la agenda política y económica, ya que estos temas se consideran "privados", no abiertos al debate en la opinión pública. Una de las tareas de la economía feminista será llevar a cabo una descentralización de los mercados que redefina la separación dicotómica entre esfera pública y privada, y reivindique la labor reproductiva que llevan a cabo de forma mayoritaria las mujeres, para acabar con la concepción neoclásica de la economía.

En esta breve introducción a la economía feminista hemos podido comprobar cuáles son las principales problemáticas y olvidos de la teoría economía tradicional. En los siguientes subapartados trataremos de abordar dos cuestiones centrales como son la naturalización de la división sexual del trabajo y las alternativas a una racionalidad centrada en el homo oeconomicus. Esta tarea la llevaremos a cabo con el objeto de establecer una conclusión general que conciba la crisis económica y financiera actual como una crisis del proceso modernizador que ha acabado produciendo una grave crisis de los cuidados a nivel global.

\subsection{La naturalización de la división sexual del trabajo}

Las teóricas de la economía feminista identifican al contractualismo clásico y los teóricos de la teoría política moderna como promotores ideológicos de la naturalización de la división sexual del trabajo (Hartmann, 1994), que asocia diferentes tareas a los rasgos biológicos de cada grupo sexual. De este modo, la economía feminista nos permite revelar que ciertamente, "nunca existió nada parecido a una división sexual natural del trabajo, tales divisiones son, por el contrario, productos de prácticas que las naturalizan, prácticas de las que la segregación del mercado laboral en razón del sexo es simplemente un ejemplo" (Scott, 1993: 424). Sin embargo, los cuerpos de las mujeres, la maternidad y la domesticidad acabaron por ser sinónimos de feminidad, hecho que implicó la invisibilidad del trabajo de las mujeres en el hogar. Con razón de este hecho, las mujeres son tratadas como madres y amas de casa, poniendo énfasis en sus capacidades reproductivas y siendo económicamente dependientes de los hombres del núcleo familiar (Pujol, 1995).

El concepto "doble presencia" (Balbo, 1994) nos permite comprender la ambivalencia del papel de las mujeres en esta economía disociada y dicotómica, ya que aún con la inclusión de las mujeres en el espacio público se mantendrá la ontología diferencial (Nuño, 2010). En su acepción inicial, doble presencia significa considerar que la presencia de las mujeres en el empleo (ámbito productivo) se da siempre junto a su presencia en el ámbito doméstico-familiar (ámbito reproductivo). Bajo este prisma, la doble 
presencia supone una doble carga de trabajo para las mujeres que repercute en sus posibilidades de encontrar y mantener un empleo, así como de desarrollar una carrera profesional. A su vez, esta doble presencia sería indicativa de un cambio en la identidad femenina, "construida hoy no sólo sobre la base de su protagonismo en el ámbito doméstico-familiar, sino sobre una peculiar síntesis entre público y privado, entre empleo y trabajo doméstico-familiar" (Carrasquer, 2009: 30).

Sin embargo, en la actualidad la doble participación de las mujeres - en el mercado laboral y en el trabajo del hogar- que originalmente se definió como doble trabajo y posteriormente como doble presencia, se ha denominado "doble presencia/ausencia", para simbolizar el estar y no estar en ninguno de los dos lugares y las limitaciones que dicha situación comporta (Izquierdo 1998). Así pues, frente a la visión de la escuela neoclásica, la propuesta de la economía feminista desvela la nula valoración del trabajo desarrollado en el ámbito doméstico, pasando por alto el hecho de que es una actividad fundamental para la vida (Carrasco, 2014: 29). Y es que la propuesta económica feminista va más allá de la contradicción entre capitalistas y trabajadores, plantea el problema con una visión que integra a las mujeres, y que pone de relieve que la tensión clave del sistema capitalista es "la lógica del capital frente a la lógica de la vida" (Carrasco, 2014: 37); es decir, la economía sin valores y la empresa amoral por encima de la economía holística y la empresa ética. Al mismo tiempo, permite concebir a través de su propuesta política, cómo los sistemas políticos y Estados nacionales, han sentado las infraestructuras permitiendo que la ceguera de género se torne un aspecto central del mismo (Carrasco, 2014) $)^{1}$.

Sin embargo, en el seno de la teoría económica feminista existen diferentes posturas referentes a la cuestión de la invisibilidad del trabajo de cuidados dentro de la teoría económica neoclásica (Carrasco, Borderías \& Torns, 2011). Destacamos la reflexión de Federici (2004, 2013, 2018) sobre el Salario para el Trabajo Doméstico (STD), ya que es una de las teóricas clave en este marco de pensamiento. Sus trabajos se sitúan en el movimiento autónomo feminista dentro de la tradición marxista, desde donde se rechaza que patriarcado, trabajo doméstico y desigualdad sean factores desligados del capitalismo. Federici aborda el salario doméstico desde una perspectiva política, y pone de relieve algo que en algunas ocasiones es

1 Para profundizar en el diseño de los PEG e indicadores utilizados en las encuestas sobre trabajos y tiempos, se pueden consultar diversos de los trabajos de Yolanda Jubeto (2007, 2008), y la investigación de María Pazos sobre cómo afectan el diseño del IRPF y las políticas fiscales a la desigualdad de género en el caso español (Medialdea \& Pazos, 2011; Pazos, 2010). 
olvidado por parte de ciertas corrientes de la economía feminista. Esto es, reconoce que el trabajo del hogar "ha sido transformado en un atributo natural de la psique y personalidad femeninas" (Federici, 2013: 37). Esta naturalización del trabajo doméstico como aquél trabajo que debe ser desempeñado por las mujeres, tiene mucho que ver con la separación entre esfera pública y privada, pero también con la lógica del capital. En este sentido es en el que Federici (2013: 39) considera que reclamar el STD, significa rechazar el rol asignado a las mujeres por parte del capital. Mediante dicha reclamación, iniciada por las welfare mothers en los EEUU de los setenta, se visibiliza que este trabajo genera dinero para el capital, y que, por tanto, solamente cuando se revele como una cuestión política, las mujeres podrán decidir si realizar o no este tipo de trabajos.

De algún modo, la reclamación del STD es un claro ejemplo de cómo la reflexión y reivindicación feminista sobre la teoría económica puede entrar a reconfigurar los espacios sociales, políticos, culturales, económicos y empresariales en los cuales persiste la desigualdad de género y de otra índole. $Y$ es que, se trata de reivindicar la incorporación de las vivencias, experiencias y necesidades de otros grupos no tenidos en cuenta en la economía actual, para abrir paso a una economía consciente de sus límites y desafíos. De aquí se deriva también la necesaria reformulación de la racionalidad autointeresada del homo oeconomicus, tarea que llevaremos a cabo en el siguiente subapartado.

\subsection{Contra la racionalidad del homo oeconomicus}

Otra de las críticas centrales que elabora la economía feminista se dirige a la lógica del homo oeconomicus, al individuo como agente racional que predomina en la economía actual como único agente posible. La economista Cristina Carrasco trae a colación los trabajos de Julie A. Nelson con el objeto de mostrar cómo el individuo neoclásico deja fuera del modelo a las mujeres y reproduce diversas problemáticas que ya encontramos en el concepto de ciudadanía universal moderna. Dicha concepción del individuo implica una visión del agente económico egoísta, no influenciado por los sucesos que acontecen en el marco social como si se tratase de un "hongo hobbesiano", entendido como hongos que surgen espontáneamente y que maduran sin necesidad de ninguna interrelación (Nelson, 1993: 292). Incluir a las mujeres en esta esfera, al modo que reivindicaba Gilligan en referencia a los procesos de razonamiento moral (MedinaVicent, 2016), supondrá la ampliación de una noción estrecha de economía que atienda a otras realidades. Así, aproximarnos al mundo de la economía desde una mirada feminista evidencia el sistema androcéntrico so- 
bre el que se basa, y nos permite reconocer que la precariedad de las mujeres responde a un conjunto de procesos que elude la sostenibilidad de la vida $^{2}$ (Carrasco, 2009: 182).

La racionalidad del homo oeconomicus se encuentra en relación a la naturalización de la división sexual del trabajo que hemos visto anteriormente. $\mathrm{Y}$ es que dicho modelo se basa en un concepto de autonomía heredero de las ideas ilustradas que propugna un modelo completamente ajeno a la experiencia de las mujeres. Una experiencia que se encuentra ligada históricamente al desarrollo del trabajo de cuidados, un trabajo situado fuera de las fronteras construidas por la economía sobre qué es trabajo y que no, y que escapan del análisis económico actual. Así pues, el concepto de autonomía ilustrado (Sánchez, 2008: 18) contiene un sesgo androcéntrico que determina el papel de las mujeres en la vida social a través de un discurso naturalista. En la obra Emilio (1762) de Rousseau (2011), dicho autor otorga a los hombres autonomía moral para gobernar sus propias vidas, mientras que a las mujeres, a través de la figura de Sofía, las identifica con la sujeción, con la dependencia y la falta de autonomía: "Al tratar la cuestión de la naturaleza femenina a través de Sofía, Rousseau incurre repetidamente en lo que, desde Hume, se conoce como la falacia naturalista" (Cobo, 1995: 229; Amorós, 2000: 409), esto es, derivar proposiciones prescriptivas - juicios de valor- de enunciados descriptivos - juicios de hecho.

Rousseau va a insistir en que es la anatomía la que marca las diferencias, no sólo físicas, sino morales, entre hombres y mujeres. Si la educación de Emilio debe estar orientada a cultivar su independencia de criterio frente a los prejuicios, la de Sofía es meramente instrumental, y su destino está inexorablemente marcado por la dependencia y la sujeción (Sánchez, 2008: 23-24). Por tanto, la sujeción de las mujeres deviene de su condición sexual, es decir, de las funciones reproductivas que les son asignadas. El concepto de autonomía que se fundamenta en estos años es excluyente, ya que solamente otorga la capacidad de decisión sobre la vida y el cuerpo de uno/a mismo/a los hombres. De esta forma, la responsabilidad de cuidados que es puesta en manos de las mujeres, las torna seres dependientes e imposibilita el reconocimiento de su aporte al desarrollo económico. Ésta es una de las razones centrales de la desigualdad y esto nos remite a la visión del sujeto político moderno basado en un concepto de igualdad y autonomía sesgada y androcéntrico.

2 El concepto de sostenibilidad de la vida resulta trascendental dentro de la economía feminista, y en los últimos años se está desarrollando en confluencia con la teoría de las capacidades de Amartya Sen (Carrasco, 2001, 2016; León, 2009). 
Consecuentemente, existe una relación directa entre la formación del Estado moderno, la separación entre economía y ética, el auge del homo oeconomicus y del sujeto universal moderno, con la desigualdad de género imperante en nuestra sociedad. Una desigualdad que condiciona la vida de mujeres y hombres, pero, sobre todo, impide la igual inserción de las primeras en el ámbito laboral. La economía feminista propone una metodología alternativa que reescriba los significados de objetividad y universalidad, realidad que nos permite poner en valor el cuidado también dentro de la economía. No obstante, para construir una visión más humana de la economía y considerar el cuidado como una necesidad social "es necesario situarse en una lógica no mercantilizada de la vida, en la que las cuestiones relativas a la subsistencia, la solidaridad, el altruismo, la reciprocidad, los afectos y la sostenibilidad de la vida no estén supeditadas a la acumulación de capital, sino al bienestar global" (Castro, 2013: 6).

En definitiva, para repensar la teoría económica en sus términos actuales, se hace necesario ampliar el objeto de análisis y atender a todos los aportes que las mujeres y otros grupos realizan. De cualquier otro modo, se construye un saber completamente ajeno al devenir de las sociedades, un saber que reproduce las dicotomías de género y agranda las dificultades a las que debe hacer frente la ciudadanía en un contexto de neoliberalismo y precariedad feroces (Ingala, 2016; Alonso, Fernández Rodríguez \& Ibáñez, 2017; Briales, 2017).

CONCLUSIÓN: LA CRISIS DE LOS CUIDADOS COMO ALERTA PARA LA LUCHA FEMINISTA

A partir de las cuestiones expuestas con anterioridad se puede llegar a entender la crisis económico-financiera actual como una crisis del proyecto modernizador que se centra en un "sujeto privilegiado en torno al cual se concentran el poder y los recursos: un sujeto blanco, burgués, varón, adulto, con una funcionalidad normativa, heterosexual, etc." (Pérez Orozco, 2014a: 180). Así, el modelo de universalidad heredero de la modernidad muestra sus fisuras y la necesidad de incorporar a otros grupos en la ecuación de forma igualitaria. Se revela que la preeminencia de un concepto de ciudadanía pretendidamente universal, pero con tintes androcéntricos, y la prevalencia de un modelo de racionalidad económica basada en el modelo del homo oeconomicus, nos ha conducido a una crisis de los cuidados a nivel global que acentúa la desigualdad no solamente de género, sino también de pobreza. En este momento histórico se hacen evidentes las carencias de una teoría política que pugna por una ciudadanía universal y una teoría económica que pugna por un espacio económico desprovisto 
de valores. Estas construcciones culturales fundamentan una lógica mundial que imposibilita la construcción de proyectos de vida factibles para las mujeres, las personas ciudadanas de países empobrecidos y aquellos/as que necesitan ser cuidados.

Por esta razón, sostenemos junto a la propuesta de la economía feminista que "frente a la existencia de un discurso hegemónico que legitima y fomenta un sistema que es insostenible e injusto, es urgente la confluencia y el diálogo de miradas críticas que arranquen desde fuera de los mercados" (Pérez Orozco, 2011: 31). Por tanto, resulta central poner en evidencia la crisis de los cuidados que estamos viviendo a nivel global, muestra de los derroteros de la economización de la sociedad y la renuncia a la ética, pasando por alto lo vital de los cuidados como herramienta para el bienestar social y el mantenimiento de las sociedades democráticas. Cabe señalar que dicha crisis se refiere a:

La puesta en evidencia y agudización de las dificultades de amplios sectores de la población para cuidarse, cuidar o ser cuidados. Dichas dificultades se manifiestan a raíz de una desestabilización del modelo tradicional de reparto de las responsabilidades sobre los cuidados y una reestructuración del conjunto del sistema socioeconómico, sin que se haya alterado por ello la división sexual del trabajo en los hogares ni la segmentación de género en el mercado laboral (Ezquerra, 2011: 176).

Así pues, la reestructuración de las tareas de cuidado en el conjunto del sistema socioeconómico implica una agudización de las diferencias entre países debido a las políticas de deslocalización empresarial y los movimientos migratorios que se producen desde el Tercer Mundo hacia Occidente. Esto quiere decir que se ha trasladado la responsabilidad de cuidado de las mujeres occidentales a las mujeres inmigrantes procedentes de Asia, África y América Latina. Esta Nueva División Internacional del Trabajo se puede ver ejemplificada en el cuidado de los mayores en las sociedades occidentales, que recae hoy en día en manos de inmigrantes de países empobrecidos, mujeres que se encargan del cuidado de los mayores que están al cargo de esas mujeres europeas que trabajan fuera del hogar. Como se puede observar, esta situación no transforma la desigualdad de género de base, sino que la incrementa en su intersección con otras variables de pobreza, territorialidad y precariedad a nivel global.

Así, las mujeres del Sur "se han convertido en las trabajadoras domésticas del Norte" (Federici, 2013: 147), permitiendo a los gobiernos reducir la inversión en reproducción, y reducir su responsabilidad para con el cuidado, un tema de gran trascendencia social. Este fenómeno responde no sólo a la lógica económica de la racionalidad autointeresada que invisibiliza 
el trabajo de cuidados, sino también a una pérdida de responsabilidad del Estado en las cuestiones de cuidado de la ciudadanía. De este modo, estamos asistiendo a la configuración de sociedades cada vez más precarias (Muñoz-Rodríguez \& Santos, 2017, 2019; Medina-Vicent, 2018a) donde la lógica de la gestión empresarial ha pasado a formar parte de la identidad de los sujetos (Fernández Rodríguez \& Medina-Vicent, 2017; García Ferrer, 2017), que sirve de excusa a los Estados para no actuar en la gestión de las necesidades de cuidados que lanza gran parte de la ciudadanía.

Por tanto, estamos asistiendo a un proceso global de crisis económica que evidencia la crisis de dos de las bases sobre las que se ha construido esta investigación: la ciudadanía universal moderna y la racionalidad económica autointeresada. Se desvela así la urgencia de replantear los debates en torno a la economía y el bienestar social de las personas desde la perspectiva de género. En este contexto resulta transcendental repensar el papel de las mujeres y otros grupos en la escena social, y acabar con la división impuesta por la nueva reestructuración global de los cuidados entre las mujeres, que debilita la posibilidad de una solidaridad feminista global (Federici, 2013: 110), y abrir paso a un feminismo cosmopolita que pueda hacer frente a estas disyuntivas y retos (Reverter-Bañón, 2017; ReverterBañón \& Medina-Vicent, 2016). Por esta razón, consideramos que la reflexión feminista se debe situar en un marco de trabajo anticapitalista, pues las desigualdades que se viven en el Sur deben suponer para las feministas del Norte una toma de conciencia del enemigo común: el neoliberalismo.

\section{REFERENCIAS}

Alonso, L. E., Fernández Rodríguez, C. J., \& Ibáñez Rojo, R. (2017). Juventud y percepciones de la crisis: precarización laboral, clases medias y nueva política. EMPIRIA Revista de Metodología de Ciencias Sociales, (37), 155-178. https://doi.org/empiria.37.2017.18983

Amorós, C. (1982). Rasgos patriarcales del discurso filosófico: notas acerca del sexismo en filosofía. En M. Á. Durán (Ed.), Liberación y utopia (pp. 35-59). Madrid: Akal.

Amorós, C. (2000). Tiempo de feminismo. Sobre feminismo, proyecto ilustrado y postmodernidad. Madrid: Ediciones Cátedra.

Balbo, L. (1994). La doble presencia. En C. Borderías, C. Carrasco, \& C. Alemany (Eds.), Las mujeres y el trabajo. Rupturas conceptuales (pp. 503-514). Madrid: Icaria.

Beltrán, E. (1994). Público y privado. Sobre feministas y liberales: argumentos en un debate acerca de los límites de lo político. Doxa: Cuadernos de Filosofía del Derecho, 1(15-16), 389-405.

Briales, Á. (2017). Emprendeudores fracasados: individualización neoliberal en los discursos sobre el desempleo. Recerca, Revista de pensament $i$ analisi, (20), 
79-104. https://doi.org/10.6035/Recerca.2017.20.5

Calvo, P. (2010). ¿Homo economicus u homo reciprocans? Contribución de la ética y la neuroeconomía al principio de reciprocidad. En Á. Sierra \& Y. Romero (Eds.), Actas del $V$ Congreso Internacional de la Sociedad Académica de Filosofía: razón, crisis y utopía (pp. 97-110). Tenerife: Universidad de la Laguna. Calvo, P. (2012). ¿Es posible otra racionalidad económica? En EBEN (Ed.), XIX Congreso EBEN: Transformar el mundo, bumanizar la ciencia (pp. 1-23). Barcelona: Universitat Politècnica de Catalunya.

Calvo, P. (2018). The Cordial Economy. Ethics, Recognition and Reciprocity. Cham: Springer.

Carrasco, C. (2001). La sostenibilidad de la vida humana: ¿un asunto de mujeres? Mientras tanto, (82), 43-70.

Carrasco, C. (2006). La economía feminista: una apuesta por otra economía. En M. J. Vara (Ed.), Estudios sobre género y economía (pp. 29-62). Madrid: Akal.

Carrasco, C. (2009). Mujeres, sostenibilidad y deuda social. Revista de Educación, No Extraor, 169-191.

Carrasco, C. (2014). La economía feminista: ruptura teórica y propuesta política. En C. Carrasco (Ed.), Con voz.propia. La economía feminista como apuesta teórica y politica (pp. 25-48). Madrid: La Oveja Roja.

Carrasco, C. (2016). Sostenibilidad de la vida y ceguera patriarcal. Una reflexión necesaria. Atlánticas. Revista Internacional de Estudios Feministas, 1(1), 34-57.

Carrasco, C., Borderías, C. \& Torns, T. (2011). El trabajo de cuidados. Historia, teoría y politicas. Madrid: Ediciones Catarata.

Carrasco, C. \& Díaz, C. (Eds.) (2017). Economía Feminista. Desafíos, Propuestas, Alianzas. Madrid: Ediciones Entrepueblos.

Carrasquer, P. (2009). La doble presencia. El trabajo y el empleo femenino en las sociedades contemporáneas. Barcelona.

Carrasquer, P., Torns, T., Tejero, E., \& Romero, A. (1998). El trabajo reproductivo. Papers, 55, 95-114. https://doi.org/10.5565/rev/papers.1934

Castro, C. (2013). Imaginando el cambio de modelo: algunas ideas sobre la economía de la igualdad. Transversales, (27), 5-8.

Castro, C. (2016). Potencialidad género-transformativa de las políticas públicas. Atlánticas. Revista Internacional de Estudios Feministas, (1), 108-140.

Cobo, R. (1995). Fundamentos del patriarcado moderno. Jean-Jacques Rousseau. Madrid: Cátedra.

Conill, J. (2003). El sentido ético de la economía en tiempos de globalización. Daimon. Revista Internacional de Filosofía, (29), 9-15.

Conill, J. (2004). Horiozontes de economía ética. Aristóteles, Adam Smith, Amartya Sen. Madrid: Tecnos.

Cortina, A. (1994). Ética de la empresa: claves para una nueva cultura empresarial. Madrid: Trotta.

Ezquerra, S. (2011). Crisis de los cuidados y crisis sistémica: la reproducción como pilar de la economía llamada real. Investigaciones Feministas, (2), 175-194. https:/ /doi.org/10.5209/rev_INFE.2011.v2.38610

Federici, S. (2004). Calibán y la bruja. Mujeres, cuerpo y acumulación originaria. Madrid: 
Traficantes de sueños.

Federici, S. (2013). Revolución en punto cero. Trabajo doméstico, reproducción y luchas feministas. Madrid: Traficantes de sueños.

Federici, S. (2018). El patriarcado del salario. Críticas feministas al marxismo. Madrid: Traficantes de sueños.

Fernández Rodríguez, C. J. y Medina-Vicent, M. (2017). Los nuevos discursos del management: difusión, impactos y resistencias. Recerca. Revista de pensament $i$ analisi, (20), 7-14. http://dx.doi.org/10.6035/Recerca.2017.20.1

García-Marzá, D. (2004). Ética empresarial: del diálogo a la confianza. Madrid: Trotta.

García Ferrer, B. (2017). El precio del progreso: de la «virtualización del mundo» al «zombismo hiperindividualista». Recerca. Revista de pensament $i$ anàlisi, (20), 105-126.

Gintis, H. (2000). The Evolution Theory Games: A Problem-Centered Introduction to Modeling Strategic Interaction. New Jersey: Priceton University Press.

Hartmann, H. I. (1981). The Family as the Locus of Gender, Class, and Political Struggle: The Example of Housework. Signs, 6(3), 366-394. https://doi.org/10.1086/493813

Hartmann, H. I. (1994). Capitalismo, patriarcado y segregación de empleos por sexo. En C. Borderías, C. Carrasco, \& C. Alemany (Eds.), Las mujeres y el trabajo. Rupturas conceptuales (pp. 253-294). Madrid: Icaria.

Hewitson, G. J. (1999). Feminist Economics: Interrogating the Masculinity of Rational Economic Man. Cheltenham: Edward Elgar Publishers.

Ingala, E. (2016). Cuerpos vulnerables y vidas precarias. ¿Un retorno de lo humano en la filosofía de Judith Butler. Daimon. Revista Internacional de Filosofía, Suplemento 5, 879-887.

Izquierdo, M. J. (1998). El malestar en la desigualdad. Madrid: Cátedra.

Johansen, L. (1977). The Theory of Public Goods: Misplaced Emphasis? Journal of Public Economics, 7(1), 147-52.

Jubeto, Y. (2007). Experiencias europeas en presupuestos con enfoque de género: una revisión crÍtica. Aequalitas: Revista jurídica de igualdad de oportunidades entre mujeres y hombres, (21), 6-24.

Jubeto, Y. (2008). Los presupuestos con enfoque de género: una apuesta feminista a favor de la equidad en las políticas públicas. Cuadernos de trabajo de Hegoa, (43), 5-32.

León, M. (2009). Cambiar la economía para cambiar la vida. En A. Acosta \& E. Martínez (Eds.), El buen vivir: una vía para el desarrollo (pp. 63-92). Quito: AbyaYala.

Locke, J. (2014). Segundo Tratado sobre el Gobierno Civil. Madrid: Alianza.

Mateos Sillero, S. (2013). Construcción de la feminidad normativa y sujeto político. Investigaciones Feministas, (4), 297-321. https://doi.org/10.5209/rev_INFE.2013.v4.43894

Medialdea, B., \& Pazos, M. (2011). ¿Afectan los impuestos a la (des)igualdad de género? El caso del IRPF español. Madrid: Instituto de Estudios Fiscales.

Medina-Vicent, M. (2013). Habermas y el feminismo. Encuentros y desencuentros entre la teoría crítica habermasiana y la teoría política 
feminista. Fòrum de Recerca, (18), 3-26.

Medina-Vicent, M. (2016). La ética del cuidado y Carol Gilligan: una crítica a la teoría del desarrollo moral de Kohlberg para la definición de un nivel moral postconvencional contextualista. Daimon. Revista Internacional de Filosofía, (67), 83-98.

Medina-Vicent, M. (2018a). Cuerpos y mercado en la era de la precariedad. Asparkia. Investigació Feminista, (33), 13-26. http://dx.doi.org/10.6035/Asparkia.2018.33.1

Medina-Vicent, M. (2018b). Flirting with Neoliberalism: The Transfiguration of Feminist Political Awareness. NORA. Nordic Journal of Feminist and Gender Research, 26(1), 69-75. https://doi.org/10.1080/08038740.2018.1424728

Muñoz-Rodríguez, D., \& Santos-Ortega, A. (2017). Las cárceles del capital humano: trabajo y vidas precarias en la juventud universitaria. Recerca. Revista de pensament i anàlisi, (20), 59-78. https:/ /doi.org/10.6035/Recerca.2017.20.4

Muñoz-Rodríguez, D., \& Santos-Ortega, A. (2019). Precariedad en la era del trabajo digital. Recerca. Revista de pensament $i$ anàlisi, 24(1), 1-13. http://dx.doi.org/10.6035/Recerca.2019.24.1.

Miedes, B., \& Flores, D. (2013). La invención del homo economicus y la expulsión de la ética de la economía. ¿Un camino sin retorno? Revista de Economía Mundial, (35), 229-248.

Millett, K. (1995). Política sexual. Madrid: Cátedra.

Nelson, J. A. (1993). Gender and Economic Ideologies. Review of Social Economy, 51(34), 287-301.

Nuño, L. (2010). El mito del varón sustentador. Barcelona: Icaria.

Pateman, C. (1995). El contrato sexual. México DF: Anthropos.

Pazos, M. (2010). Fiscalidad y equidad de género. Recuperado a partir de https://www.fundacioncarolina.es/wp-

content/uploads/2014/08/DT43.pdf

Pérez Orozco, A. (2004). Estrategias feministas de deconstrucción del objeto de estudio de la economía. Foro Interno, (4), 87-117.

Pérez Orozco, A. (2011). Crisis multidimensional y sostenibilidad de la vida. Investigaciones Feministas, 2, 29-53. https://doi.org/10.5209/rev_INFE.2011.v2.38603

Pérez Orozco, A. (2014a). Crisis multidimensional y ajuste feminizado. En C. Carrasco (Ed.), Con voz.propia. La economía feminista como apuesta teórica y politica (pp. 171-192). Madrid: La Oveja Roja.

Pérez Orozco, A. (2014b). Subversión feminista de la economia. Aportes para un debate sobre el conflicto capital-vida. Madrid: Traficantes de sueños.

Pujol, M. (1995). In the Margin! En E. Kuiper \& J. Sap (Eds.), Out of the Margin. Feminist Perspectives on Economics (pp. 12-24). London and New York: Routledge.

Rawls, J. (2009). Lecciones sobre la Historia de la Filosofía Política. Barcelona: Paidós.

Reverter-Bañón, S. (2008). Mujeres contra el Estado. En J. Caballero Guiral \& S. Reverter-Bañón (Eds.), Dones contra l'Estat (pp. 5-20). Castelló de la Plana: Publicacions de la Universitat Jaume I. 
Reverter-Bañón, S. (2009). El ruido de la teoría feminista. Cuadernos Koré, 1(1), 53-68.

Reverter-Bañón, S. (2017). Cosmopolitismo Feminista contra Globalización. Araucaria, 19, 301-325. https://doi.org/10.12795/araucaria.2017.i37.15

Reverter-Bañón, S. y Medina-Vicent, M. (2016). La perspectiva de género como una mirada crítica al mundo. Asparkía. Investigació Feminista, (29), 11.16. http:/ /dx.doi.org/10.6035/Asparkia.2016.29.1

Rousseau, J.-J. (2011). Emilio o de la educación. Madrid: Alianza.

Sánchez, C. (2008). Genealogía de la vindicación. En E. Beltrán, V. Maquieira, S. Álvarez, \& C. Sánchez (Eds.), Feminismos (pp. 17-74). Madrid: Alianza Editorial.

Scott, J. W. (1993). La mujer trabajadora en el siglo XIX. En G. Duby \& M. Perrot (Eds.), Historia de las mujeres en Occidente. Madrid: Taurus.

Sen, A. (1986). Los tontos racionales: Una crítica de los fundamentos conductistas de la teoría económica. En F. Hahn y M. Hollis (Comp.), Filosofía y Teoría Económica (pp. 172-217). México: Fondo de Cultura Económica.

Young, I. M. (1990). Imparcialidad y lo cívico público. Algunas implicaciones de las críticas feministas a la teoría moral y política. En S. Benhabib \& D. Cornell (Eds.), Teoría feminista y teoría crítica: ensayos sobre la politica de género en las sociedades de capitalismo tardío (pp. 89-117). València: Alfons el Magnànim.

Zein-Elabdin, E. (2003). The Difficulty of a Feminist Economics. En D. K. Barker \& E. Kuiper (Eds.), Toward a Feminist Philosophy of Economics (pp. 321338). London and New York: Routledge.

Sumario: Introducción; 1. El nacimiento de una racionalidad económica autointeresada; 2. Las bases universales de la ciudadanía moderna; 3. La propuesta crítica de la economía feminista; 3.1 La naturalización de la división sexual del trabajo; 3.2 Contra la racionalidad del homo oeconomicus; Conclusión: la crisis de los cuidados como alerta para la lucha feminista; Referencias. 